\title{
Opinion piece: What the doctor didn't order
}

\author{
Kate Bull ${ }^{1 *}$ (D) and Stuart Watson ${ }^{2}$
}

Looking back at the last century, the drive to advance the treatment of congenital heart disease (CHD) was the exclusive province of doctors (often surgeons) and researchers and their funders. Early patients and their families, while not exactly commodities, were not agents.

Now when we look at the prospect for further advances in the current century, the traditional, medically based agencies are still delivering innovation - percutaneously implantable valves, stem cell grafts, mechanical devices. These are mostly treatments for end-stage disease that everyone hopes that few will need. But if we gauge medical progress by its capacity to improve the length and quality of the lives of many patients, there is a new kid on the block. The new agent for change is the capacity of patient communities to act together. Surfing on the potential of the Internet to put people in touch with each other, support groups move information around. They put the right information in front of the right people at the time when they need it, in a language that they understand - and give them courage to act on it.

Many bona fide stakeholders in the enterprise of CHD have an Internet presence. The Internet offers medical professionals access to journals and audit websites and we probably have some notion of the wider scope of the material that the it carries about our field - and may have our own particular prejudices about its wild-west territories. Type "Transposition of the Great Arteries" (TGA) into a search engine and featuring conspicuously will be pages from the websites of major hospitals with CHD services. Apart from the hospitals' 'advertising', the content relevant to TGA of these sites is very similar. All offer the predictable diagram, along with a very medically orientated resume of a care-plan for a child born with TGA, usually illustrated with images of smiling children.

Also appearing prominently on a CHD search will be a Wikipedia page. In the case of TGA, its entry is muddled and difficult to see as widely helpful (it may have

\footnotetext{
* Correspondence: katebull008@gmail.com

124 Riverside, Cambridge, UK

Full list of author information is available at the end of the article
}

been drafted by a medical geneticist); the Wikipedia pages on the Mustard, Senning and Switch (under the Jaetene name) operations are a little more coherent.

Next up are sites promoting charities, research or advocacy. All typically offer the same core information about TGA and are a reasonably good source of summaries written in natural language rather than medical jargon. Some of it is a little dry and dusty; these organisations are telling the reader stuff, not promoting a conversation. The pictures they paint of life with $\mathrm{CHD}$ are often a little varnished; again the photos are resolutely upbeat.

If you want a less sanitised account of actually living with CHD, you need to reach one of the support groups. Doctors may well be familiar with groups that originated around individual hospitals or were set up by national organisations; these associations were often started by doctors working alongside committed parents of $\mathrm{CHD}$ patients. Most now have an Internet presence, an executive board that includes a doctor, and a mission statement that will often include advocacy for a discernible patient group. They may have a bulletin board fielding questions, often moderated by someone with clinical qualifications.

Though each of these types of website serves a function, none offers quite the kind of support that I want to describe. A few years ago as an about-to-retire paediatric cardiologist writing a book [1], I (KB) began to interview 'graduates' of childhood services and have these people to thank for opening a window into a world I might never otherwise have appreciated.

To access these support groups, you must turn to Facebook. Some CHD Facebook groups welcome people of all ages, conditions and treatment histories; others are focused in some way - by age, diagnosis, geography, even gender. With very few exceptions, they do not have doctors as members nor do they function under the auspices of medical organisations; any governance they have has been entirely of their own making. Each has its own character; amounts of traffic vary enormously. Type "Transposition of the Great Arteries" into Facebook and 
the search returns 14 English-medium groups; type in "Mustard operation" and the search returns four (including one for 'having-had-a-transplant-post-Mustard' - 38 members). Not all the listed TGA groups are very active, but there are six each with over 300 members and over 50 posts uploaded in the past 30 days. They are all 'closed' groups - you cannot browse their content without joining the group, and to join you need to convince an administrator that you 'qualify' - or in my own case at least promise to be a benign presence. (Despite being properly 'introduced' by a patient I had interviewed, I took myself off the "CHD adults 50 and over" group when another member flagged up her concern that as a doctor I would sugar-coat the experiences I learned about.)

Thanks to an invitation by a patient, I (KB) have been a member of the "Mustard and Senning Survivors" Facebook group for about 4 years. There are currently over 1300 group members, spread over 4 continents. No single doctor or hospital service can begin to compete with the tonnage of life experience of this out-of-the-ordinary circulation that this community hold. Their conversations are in English, which the Scandinavians, Portuguese and Germans seem to manage effortlessly.

The group was created in 2009 by SW; at the time he was on the New Zealand transplant waiting list after his childhood Mustard operation. Though already a veteran of supporting kids, teens, adults and families with CHD, until Facebook became a force in the world, SW could see no easy way of putting Mustard and Senning survivors in touch with each other. Starting with 20 or so personal contacts, the group grew by about 100 members/year for the first few years, people joining through the Facebook grapevine. More recently (and since group administrators put links into the Wikipedia page) another flood of members has joined, so that the group's size has almost doubled in the past three years.

As the group grew, 'rules of engagement' were clarified and more administrators co-opted, tasked with admitting new members and occasionally moderating 'conversations'. Members are required to sign up to a nobullying, no trash-talk, no-politics dialogue. Very occasionally you notice that an exchange that may have been turning sour has been simply taken off the page by the administrators; this is done with a light touch in the name of making the group a "safe space" while allowing through a lot of poking of fun. One administrator (an academic librarian with a $\mathrm{PhD}$ ) maintains a library of journal papers, another (a Reader in Theoretical Physics) understands stochastic models of atrial fibrillation and a Senning survivor (himself an anaesthetist) can clarify any medical misconceptions, should they crop up.

Just how representative the members of the group are of the worldwide Mustard and Senning community is difficult to tell. They certainly cover the whole spectrum of ages of Mustard and Senning survivors. Many give a 'shout' when their birthday comes around; the oldest I have noticed was 63. Some members have had a clear run since their operation with no drama or further surgery. Others have had a tough time - some transplanted, others waiting, more being assessed. There are a couple of survivors of banding-and-switching, but the whole group recently 'watched' the long drawn out failure and subsequent death of a member who embarked on this course. The operative decision had been discussed with the group. As things slipped postoperatively, the group 'admins' managed the updates as they arrived from the family, sharing only significant information to ensure that the dialogue did not become sidetracked. In response, the group offered the patient's family truly worldwide support, which continues to the present. A group member attended the funeral.

So what do they talk about? Almost daily, someone is asking for some sort of advice - and what a resource! "I'm pregnant and seeing my obstetrician for the first time; is there anything particular I should ask them?" Within $24 \mathrm{~h}$ there are ten pertinent, practical responses, borne of personal experience. "How bad do you have to be before they consider you for a transplant?", "Anyone had a baffle stented?", "Bi ventricular pacing - good or what?" - all answered promptly with useful discussion. Members ask about what medical reports actually mean - often including a scan of their personal result sheets. They enquire about drugs: "anyone on X, I'm feeling Y." They post selfies from their hospital beds and moan about chaotic outpatient clinics. They ask for recommendations for doctors and specialist-centres and discuss whether it is worth travelling long distances for care.

Responses to these queries vary a lot but are basically sane and well intentioned. There are clearly a few members who have gone to a lot of trouble to understand the various medical metrics that doctors use (someone who has watched their own numbers decline over their years on a transplant trajectory can give a pretty good account of VO2max and RVEF). The collective knowledge of the group gradually accumulates as a few individuals take trouble to keep track of the formal medical literature. If by their grasp of the issues, patients come to contribute to their own care and influence the services they rely on, this success will be in no small part due to the maturation of Internet support groups. I have never seen nonsense propagated.

This group knows the value of finding a doctor with the right range of experience, but keeping in touch with a specialist service remains a major challenge for $\mathrm{CHD}$ patients everywhere. A straw poll provided several stories of Mustard and Senning survivors with more than 
ten-year gaps in follow-up. Knowing more than their 'generalist' doctors - including casualty doctors - is also a challenge. "Don't kid me, the aorta comes off the left ventricle..." is not what a patient in crisis wants to hear.

Discussions like these relate broadly to 'staying alive' but actually only constitute a minority of messages to the group. Most posts relate to 'living'. Family life (births and marriages), holidays, "what did you do at the weekend?" all feature - with photos. There are also "my ankles are awful" and "my kids have seen me carried off in an ambulance - what do you tell yours?" There are moans and credits about workplaces, about fitness and weight loss, about insurance and existential anxieties. Conversations circulate around this diverse range of people from different continents, with completely different work and family situations yet bound together by a single commonality. As an observer, this appears to me as extraordinary. By most standards these people are complete strangers, yet their solidarity clearly helps "nobody else understands" is a very frequent refrain.

So what is my point? I want to make the case that virtual networks of patients have more potential to improve the lot of CHD survivors than any of the high-tech medical innovations that are on the horizon. Just as the telephone changed the reach of friendship, social media has brought something positive and new - even to medicine. What is so interesting is that the medical profession have no control of these virtual communities.

The departing Medical Director of NHS England recently claimed that the greatest innovation since its inception in 1948 was not the availability of antibiotics or anti-cancer drugs or joint replacement surgery, but the NHS itself. I am not one to believe that medicine is 'what doctors do to patients', rather that medicine is 'what it lets patients do with their lives.' So here I suggest that the greatest innovation in CHD in the current century, the one with the most far-reaching impact on the health of people (now mainly adults) with CHD has been the flourishing of Internet support groups.

$S W$. The one overriding thing this group does over and over and over, is connect people who thought they were alone in this journey; that is all I ever wanted the group to be when I started it. What it has become is beyond my wildest dreams; something I am so proud of. I will continue to ensure that it can provide a necessary function in the wellbeing of TGA adults for as long as I am able.

\section{Abbreviations}

CHD: Congenital heart disease; KB: Kate Bull; RVEF: Right ventricular ejection fraction; SW: Stuart Watson; TGA: Transposition of the great arteries;

VO2max: Maximal rate of oxygen consumption
Authors' contributions

SW started the group that is a major focus of this piece. KB and SW together drafted the article and agreed the final version. Their individual contributions are specified in the text.

Ethics approval and consent to participate

Not applicable.

Competing interests

The authors declare that they have no competing interests.

\section{Publisher's Note}

Springer Nature remains neutral with regard to jurisdictional claims in published maps and institutional affiliations.

Author details

${ }^{1} 24$ Riverside, Cambridge, UK. ${ }^{2}$ Morrinsville, New Zealand.

Received: 2 February 2018 Accepted: 27 April 2018

Published online: 03 July 2018

Reference

1. Bull K. Open Hearts. London: Elliott and Thompson; 2016.
Ready to submit your research? Choose BMC and benefit from:

- fast, convenient online submission

- thorough peer review by experienced researchers in your field

- rapid publication on acceptance

- support for research data, including large and complex data types

- gold Open Access which fosters wider collaboration and increased citations

- maximum visibility for your research: over 100M website views per year

At BMC, research is always in progress.

Learn more biomedcentral.com/submissions 